\title{
Failure analysis of multiple delaminated composite plates due to bending and impact
}

\author{
P K PARHI, S K BHATTACHARYYA* and P K SINHA \\ Department of Aerospace Engineering, *Department of Civil Engineering, Indian Institute of Technology, \\ Kharagpur 721 302, India
}

\begin{abstract}
The present work aims at the first ply failure analysis of laminated composite plates with arbitrarily located multiple delaminations subjected to transverse static load as well as impact. The theoretical formulation is based on a simple multiple delamination model. Conventional first order shear deformation is assumed using eight-noded isoparametric quadratic elements to develop the finite element analysis procedure. Composite plates are assumed to contain both single and multiple delaminations. For the case of impact, Newmark time integration algorithm is employed for solving the time dependent multiple equations of the plate and the impactor. Tsai-Wu failure criterion is used to check for failure of the laminate for both the cases. To investigate the first ply failure, parametric studies are made for different cases by varying the size and number of delaminations as well as the stacking sequences and boundary conditions.
\end{abstract}

Keywords. Failure analysis; delaminated composite; bending; impact.

\section{Introduction}

Laminated composite plates are extensively used in the construction of aerospace, civil, marine, automotive and other high performance structures due to their high specific stiffness and strength, excellent fatigue resistance, long durability and many other superior properties compared to the conventional metallic materials. In general, these structures require high reliability assurance for which, the prediction of the maximum load that the structure can withstand as well as the failure process is very crucial. Due to the anisotropy of composite laminates and non-uniform distribution of stresses in laminae under flexural bending as well as other types of static/dynamic loading, the failure process of laminates is very complex. Large differences in strength and stiffness values of the fibre and the matrix lead to various forms of defect/ damage caused during manufacturing process as well as service conditions. Delamination or separation of two adjacent plies in a composite laminate is one of the most common modes of damage. The presence of delamination may reduce the overall stiffness as well as the residual strength leading to structural failure. A clear understanding of the influence of delamination on the performance of the laminates is very essential to use them efficiently in structural design applications. Although several studies are available in the literature in the field of delamination prediction and growth, effect of delamination on buckling, post-buckling deformation and delamination propagation under fatigue loading, etc the work on the effect of

*Author for correspondence delamination on the first ply failure of the laminate is scarce. A few important studies related to delaminated composite laminates are presented as follows. Tracy and Pardoen (1989), Paolozzi and Peroni (1990) and Shen and Grady (1992) investigated the effects of single delamination on the natural frequencies and modes of composite beams using the 'four-region approach'. Tenek et al (1993) used a similar approach for simply supported plates. Saravanos and Hopkins (1996) investigated the damped free vibration of delaminated beams and laminates. Krawczuk et al (1997) analysed the influence of the fatigue cracks and delaminations on the dynamic characteristics of composite laminates. Yin et al (1986) analysed the delamination buckling of composite plates using one-dimensional beam plate theory. Lee et al (1992, 1995) studied the buckling and postbuckling of axially loaded composite beam plates with multiple delaminations. Parhi et al (1999) presented the free and forced vibration analysis of laminated composite plates with multiple delaminations.

The present work is undertaken to analyse the first ply failure of composite plates subjected to transverse bending as well as low velocity impact. Both single and multiple delaminations of varying sizes placed at any location of the laminate are considered. Numerical results are generated for different parametric variations like stacking sequences, boundary conditions, etc for analysis of both the cases.

\section{Finite element formulation}

A laminated composite plate of length $a$, breadth $b$ and $h$ with $n$ arbitrarily oriented layers is considered. The plate 
axes and the layer details are illustrated in figure 1 . The $x-y$ plane coincides with the middle plane of the plate and the $z$ axis is oriented along the thickness direction. The displacements $u, v$ and $w$ at any point $(x, y, z)$ in the laminate are given by

$$
\begin{aligned}
& u(x, y, z)=u^{\theta}(x, y)+z \theta_{x}(x, y) \\
& v(x, y, z)=v^{\theta}(x, y)+z \theta_{y}(x, y), \\
& w(x, y, z)=w^{\theta}(x, y)
\end{aligned}
$$

where $u^{\theta}, v^{\theta}$ and $w^{\theta}$ denote the mid-plane displacements and $\theta_{x}$ and $\theta_{y}$ denote the rotations along the $x$ and $y$ axes, respectively. Considering first order shear deformation, the strain components in a lamina for an eight noded isoparametric quadratic plate element with five degrees of freedom per node are expressed as

$$
\begin{aligned}
& \varepsilon_{x}=\frac{\partial u}{\partial x}=\varepsilon_{x}^{0}+z k_{x}, \varepsilon_{y}=\frac{\partial u}{\partial y}=\varepsilon_{y}^{0}+z k_{y}, \\
& \gamma_{x y}=\frac{\partial u}{\partial y}+\frac{\partial v}{\partial x}=\gamma_{x y}^{0}+z k_{x y} \\
& \gamma_{x y}^{0}=\frac{\partial w}{\partial x}+\theta_{x}, \gamma_{y z}^{0}=\frac{\partial w}{\partial y}+\theta_{y}
\end{aligned}
$$

where $\varepsilon_{x}^{0}, \varepsilon_{y}^{0}$ and $\gamma_{x y}^{0}$ are mid-plane strains, $k_{x}, k_{y}$ and $k_{x y}$, the plate curvatures and $\gamma_{x z}^{0}$ and $\gamma_{y z}^{0}$ are the transverse shear strains, respectively.
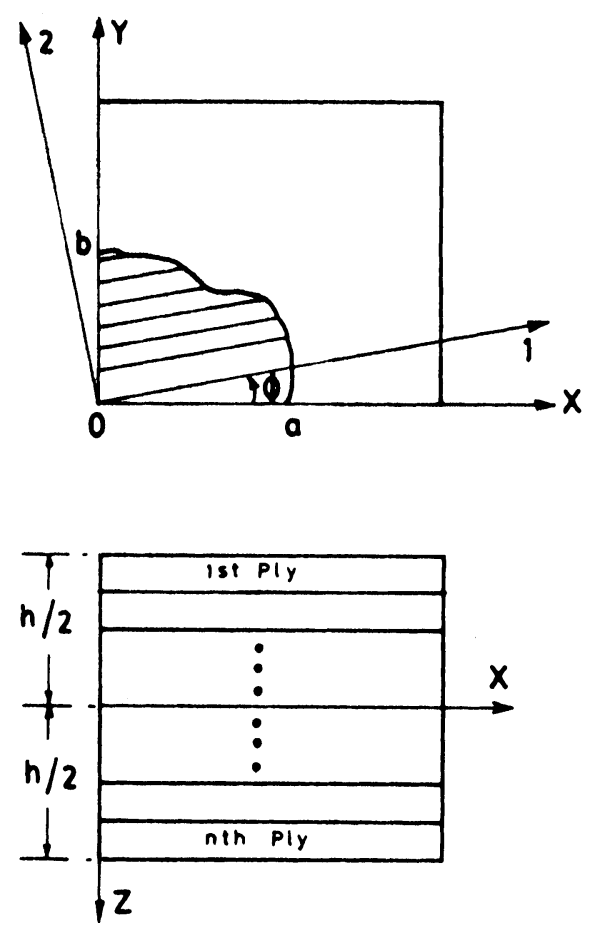

Figure 1. Plate axes and layer details.
The strains in the $k$ th lamina at a distance $z$ from the mid-plane in the matrix form are given by

$$
\left[\begin{array}{l}
\varepsilon_{x} \\
\varepsilon_{y} \\
\gamma_{x y} \\
\gamma_{x z} \\
\gamma_{y z}
\end{array}\right]=\left[\begin{array}{c}
\varepsilon_{x}^{0} \\
\varepsilon_{y}^{0} \\
\gamma_{x y}^{0} \\
\gamma_{x z}^{0} \\
\gamma_{y z}^{0}
\end{array}\right]+z\left[\begin{array}{l}
k_{x} \\
k_{y} \\
k_{x y} \\
k_{x z} \\
k_{y z}
\end{array}\right] .
$$

Here $k_{x z}$ and $k_{y z}$ are considered as zero. The shape functions $N_{1}$ (Cook et al 1989) used for different nodes are as follows.

$$
\begin{aligned}
& N_{i}=0 \cdot 25\left(1+\xi_{i} \xi\right)\left(1+\eta_{i} \eta\right)\left(\xi_{i} \xi+\eta_{i} \eta-1\right), i=1 \text { to } 4, \\
& N_{i}=0 \cdot 5\left(1-\xi^{2}\right)\left(1+\eta_{i} \eta\right), \quad i=5,7, \\
& N_{i}=0 \cdot 5\left(1-\eta^{2}\right)\left(1+\xi_{i} \xi\right), \quad i=6,8
\end{aligned}
$$

with $\xi$ and $\eta$, the local natural axes of the element and $\xi_{i}$ and $\eta_{i}$, the natural coordinates at node $i$. Straindisplacement relations are expressed in the form of midplane nodal degrees of freedom as

$$
\begin{aligned}
& \{\varepsilon\}=\sum_{i=1}^{8}\left[B_{d}\right]\left\{d_{i}\right\}, \\
& \{\varepsilon\}=\left\{\varepsilon_{x}^{\theta} \varepsilon_{y}^{\theta} \gamma_{x y}^{\theta} k_{x} k_{y} k_{x y} \gamma_{x z} \gamma_{y z}\right\}^{T}, \\
& \left\{d_{i}\right\}=\left\{u_{i}^{\theta} v_{i}^{\theta} w_{i}^{\theta} \theta_{x i} \theta_{y z}\right\}^{T}
\end{aligned}
$$

Here, $B_{d}$ is the strain-displacement matrix. The stresses at any point in the $k$ th lamina are

$$
\begin{aligned}
& \{\sigma\}=\left[\overline{Q_{i j}}\right]_{k}\left\{\varepsilon_{i}\right\}, i, j=1 \ldots 6, \\
& \{\sigma\}=\left[\sigma_{x} \sigma_{y} \sigma_{z} \tau_{x z} \tau_{y z} \tau_{x y}\right]^{\mathrm{T}},\left\{\varepsilon_{1}\right\}=\left\{\varepsilon_{x} \varepsilon_{y} \varepsilon_{z} \gamma_{x z} \gamma_{z y} \gamma_{x y}\right\}^{\mathrm{T}} .
\end{aligned}
$$

$\left[\overline{Q_{i j}}\right]_{k}$ is the off-axis stiffness of the $k$ th lamina. Here, $\varepsilon_{z}$ is zero. The elasticity matrix of the undelaminated composite plate is given by

$$
\begin{aligned}
& {[D]=\left[\begin{array}{ccc}
A_{i j} & B_{i j} & 0 \\
B_{i j} & D_{i j} & 0 \\
0 & 0 & A_{s i j}
\end{array}\right],} \\
& {\left[A_{i j} B_{i j} D_{i j}\right]=\sum_{k=1}^{n} \int_{z k-1}^{z k}\left[\overline{Q_{i j}}\right]_{k}\left(1, z, z^{2}\right), \quad i, j=1,2,6}
\end{aligned}
$$

and

$$
\left(A_{s i j}\right)=\sum_{k=1}^{n} \int_{z k-1}^{z k} \alpha\left[\overline{Q_{i j}}\right]_{k} \mathrm{~d} z, \quad i, j=4,5 .
$$

Here $\alpha$ is the shear correction factor considered as $5 / 6$. 
The element stiffness and mass matrices are given by

$$
\begin{aligned}
& {\left[K_{\mathrm{e}}\right]=\int_{-1}^{1} \int_{-1}^{1}\left[B_{\mathrm{d}}\right]^{T}[D]\left[B_{\mathrm{d}}\right] j \mathrm{~d} \xi \mathrm{d} \eta,} \\
& {\left[M_{\mathrm{e}}\right]=\int_{-1}^{1} \int_{-1}^{1}[N]^{T}[N] j \mathrm{~d} \xi \mathrm{d} \eta,} \\
& {[N]=\sum_{i=1}^{8}\left[\begin{array}{cccccc}
N_{i} & 0 & 0 & 0 & 0 \\
0 & N_{i} & 0 & 0 & 0 \\
0 & 0 & N_{i} & 0 & 0 \\
0 & 0 & 0 & N_{i} & 0 \\
0 & 0 & 0 & 0 & N_{i}
\end{array}\right]} \\
& {[\rho]=\left[\begin{array}{ccccc}
P & 0 & 0 & 0 & 0 \\
0 & P & 0 & 0 & 0 \\
0 & 0 & P & 0 & 0 \\
0 & 0 & 0 & I & 0 \\
0 & 0 & 0 & 0 & I
\end{array}\right],}
\end{aligned}
$$

with

$$
\begin{aligned}
& P=\sum_{k=1}^{n}\left(z_{k}-z_{k-1}\right) \rho_{k}, \\
& I=1 / 3 \sum_{k=1}^{n}\left(z_{k}^{3}-z_{k-1}^{3}\right) \text { and } \rho_{k},
\end{aligned}
$$

the mass per unit volume of the $k$ th lamina.

Assembling the element mass and stiffness matrices and the force vector with respect to the common global axes, the resulting equilibrium equation for bending is

$$
[K]\{u\}=\{F\} .
$$

For forced vibration,

$$
[M]\{\mathbf{u}\}+[K]\{u\}=\{F\}
$$

where $\{u\}$ and $\{\mathbf{u}\}$ are global displacement and acceleration vector, respectively.

For the impact problem, $\{F\}$ is given by

$$
\{F\}=\left[000 \ldots F_{\mathrm{c}} \ldots 000\right]^{T} \text {, }
$$

where, $F_{\mathrm{c}}$ (Yang and Sun 1982) is the contact force corresponding to the contact point.

The dynamic equilibrium of the impactor is given by

$$
m_{i} w_{i}+F_{\mathrm{c}}=0
$$

where $m_{i}$ and $w_{i}$ are impactor mass and acceleration, respectively.
Newmark's constant average acceleration method is employed to solve the dynamic forced vibration equations of the plate and the impactor in each time-step during impact.

\section{Multiple delamination modelling}

A typical laminate with $P$ number of delaminations is considered as shown in figure 2 . The nodal displacements within the sublaminate $t$ are expressed as

$$
u_{t}=u_{t}^{0}+\left(z-z_{t}^{0}\right) \theta_{x}, v_{t}=v_{t}^{0}+\left(z-z_{t}^{0}\right) \theta_{y}
$$

where $u_{t}^{0}, v_{t}^{0}$ are the mid-plane displacements of the $t$ th sub-laminate and $z_{t}^{0}(t=1$ to $p+1)$ is the distance between the mid-plane of the original laminate and the mid-plane of the $t$ th sub-laminate. Applying constraint conditions that at any delamination boundary, the transverse displacements and rotations must have the same values at a common node, we get

$$
u_{t}^{0}=u^{0}+z_{t}^{0} \theta_{x}, v_{t}^{0}=v^{0}+z_{t}^{0} \theta_{y}
$$

Combining of (13) and (14) results in

$$
\left\{\begin{array}{l}
\varepsilon_{x} \\
\varepsilon_{y} \\
\varepsilon_{x y}
\end{array}\right\}_{t}=\left\{\begin{array}{l}
\varepsilon_{x}^{0} \\
\varepsilon_{y}^{0} \\
\gamma_{x y}^{0}
\end{array}\right\}_{t}+\left(z-z_{t}^{0}\right)\left\{\begin{array}{l}
k_{x} \\
k_{y} \\
k_{x y}
\end{array}\right\},
$$

which can be written as

$$
\left\{\varepsilon^{\theta}\right\}_{t}=\left\{\varepsilon^{\theta}\right\}_{i}+Z_{t}^{0}\{k\}
$$

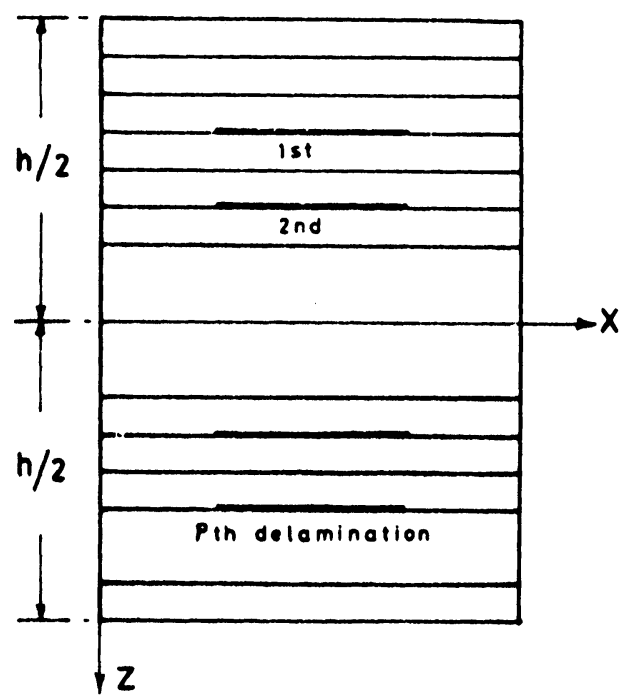

Figure 2. Laminate geometry with multiple delaminations. 
From (16), the stress and the stress resultant matrices for the $t$ th sub-laminate are calculated. The stress resultant matrices for the $t$ th sub-laminate are finally expressed as

$$
\begin{aligned}
{\left[\begin{array}{l}
N \\
M
\end{array}\right]_{t}=} & {\left[\begin{array}{ll}
A_{i j} & z_{t}^{0} A_{i j}+B_{i j} \\
B_{i j} & z_{t}^{0} B_{i j}+D_{i j}
\end{array}\right]_{t}\left\{\begin{array}{c}
\varepsilon^{0} \\
k
\end{array}\right\} } \\
\left\{\begin{array}{l}
Q_{x} \\
Q_{y}
\end{array}\right\}_{t}= & {\left[\begin{array}{ll}
A_{44} & A_{45} \\
A_{54} & A_{55}
\end{array}\right]_{t}\left\{\begin{array}{l}
\gamma_{x z} \\
\gamma_{y z}
\end{array}\right\}, } \\
{\left[A_{i j}\right]_{t}=} & \int_{\frac{h_{t}}{2}+z_{t}^{0}}\left[\overline{Q_{i j}}\right] \mathrm{d} z,\left[B_{i j}\right]_{t}=\int_{-\frac{h_{t}}{2}+z_{t}^{0}}\left[\overline{Q_{i j}}\right]\left(z-z_{t}^{0}\right) \mathrm{d} z \\
& \frac{-\frac{h_{t}}{2}+z_{t}^{0}}{2}+z_{t}^{0} \\
{\left[D_{i j}\right]_{t}=} & \int_{h_{t}}\left[\overline{Q_{i j}}\right]\left(z-z_{t}^{0}\right)^{2} \mathrm{~d} z, \quad i, j=1,2,6
\end{aligned}
$$

and

$$
\left[A_{i j}\right]_{t}=\int_{-\frac{h_{t}}{2}+z_{t}^{0}}^{\frac{h_{t}}{2}+z_{t}^{0}}\left[\overline{Q_{i j}}\right] \mathrm{d} z, \quad i, j=4,5 .
$$

Here $h_{t}$ is the thickness of the $t$ th sub-laminate.

\section{Failure criteria}

The stresses in an individual lamina are fundamental to control the failure initiation and progression in the laminate. The strength of each individual lamina was assessed separately by considering the stresses acting on it along material axes. The initial failure of a lamina (first ply failure) was governed by exceeding the maximum limit prescribed by a failure criterion. The determination of first ply failure load was very essential in understanding the failure process as well as the reliability of structures. The load that makes the first ply to fail was calculated based on one of the five commonly used failure criteria like (i) maximum stress criterion, (ii) maximum strain criterion, (iii) Hoffman's criterion, (iv) Tsai-Hill criterion and (v) Tsai-Wu criterion. Out of these, the most general and versatile one is the tensor polynomial proposed by Tsai and Hahn (1980). It was considered to be a reasonably accurate and consistent representation of failure of a lamina under biaxial stresses. The failure surface for this quadratic polynomial criterion was of the form of an ellipsoid, was independent of the ply orientations and thickness of a laminate. The Tsai-Wu failure envelope is expressed as

$$
F_{i} \sigma_{i}+F_{i j} \sigma_{i} \sigma_{j} \geq 1
$$

where $\sigma_{i}$ is the stress tensor component in the material coordinates and $F_{i}, F_{i j}$ are the strength tensor components.
For plane stress condition, the failure envelope reduces to

$$
\begin{gathered}
F_{11} \sigma_{1}^{2}+2 F_{12} \sigma_{1} \sigma_{2}+F_{22} \sigma_{2}^{2}+F_{66} \sigma_{6}^{2}+F_{1} \sigma_{1}+F_{2} \sigma_{2} \geq 1, \\
F_{11}=\frac{1}{X_{\mathrm{T}} X_{\mathrm{C}}}, \quad F_{12}=-\frac{1}{2}\left(X_{\mathrm{T}} X_{\mathrm{C}} Y_{\mathrm{T}} Y_{\mathrm{C}}\right)^{1 / 2} \\
F_{22}=\frac{1}{Y_{\mathrm{T}}}-\frac{1}{Y_{\mathrm{C}}}, \quad F_{66}=\frac{1}{S^{2}}, \\
F_{1}=\frac{1}{X_{\mathrm{T}}}-\frac{1}{X_{\mathrm{C}}}, \quad F_{2}=\frac{1}{Y_{\mathrm{T}}}-\frac{1}{Y_{\mathrm{C}}} .
\end{gathered}
$$

Here $X_{\mathrm{T}}, X_{\mathrm{C}}$ are lamina normal strengths in tension, $X_{\mathrm{C}}$, $Y_{\mathrm{C}}$ are normal strengths in compression and $S$ is the in-plane shear strength, respectively in the material coordinates.

\subsection{Ply stresses}

The stresses in the fibre direction $1-2$ in the $k$ th lamina were found by multiplying the transformation matrix as given with the stresses determined at different points of the lamina in the $x-y$ coordinates.

$$
\left\{\begin{array}{l}
\sigma_{1} \\
\sigma_{2} \\
\sigma_{3}
\end{array}\right\}_{k}=\left[\begin{array}{ccc}
m^{2} & n^{2} & 2 m n \\
n^{2} & m^{2} & -2 m n \\
-m n & m n & m^{2}-n^{2}
\end{array}\right]\left\{\begin{array}{l}
\sigma_{x} \\
\sigma_{y} \\
\tau_{x y}
\end{array}\right\}_{k} .
$$

Here, $m$ and $n$ denote cos and sin of the angle $\phi$ made by the fibres with the $x$ axis in each lamina. The lamina stresses along material axes in each ply were applied to the failure criterion to check for ply failure.

\section{Numerical results and discussion}

Computer codes were developed to generate the numerical results to study the first ply failure in a laminate for transverse bending and impact. The accuracy of the present formulation was checked for bending, free and forced vibration as well as the first ply failure results available in the literature. For computing the numerical results, the centrally located single and multiple delaminations were considered. For single mid-plane delamination, delaminations of $6.25 \%, 25 \%$ and $56 \cdot 25 \%$, respectively of the total plate area were assumed.

The effect of multiple delaminations on the first ply failure was analysed considering three types of delaminations, i.e. (i) a single mid-plane delamination, (ii) three uniform delaminations located below the 8th, 10th and 12 th plies and (iii) five uniform delaminations located below the 6 th, 8 th, 10th, 12th and 14 th plies, respectively along the thickness of the laminate. The area of delamination considered in each delamination interface was the same for each case. 
The graphite-epoxy lamina properties and the plate geometry used are given here. $E_{1}=172.5 \mathrm{GPa}, E_{2}=$ $E_{3}=6.9 \mathrm{GPa}, \quad G_{12}=G_{13}=3.45 \mathrm{GPa}, \quad G_{23}=1.38 \mathrm{GPa}$, $v_{12}=0 \cdot 25, \quad X_{1}=X_{\mathrm{C}}=1450 \mathrm{MPa}, \quad Y_{\mathrm{T}}=X_{\mathrm{C}}=1450 \mathrm{MPa}$, $Y_{\mathrm{T}}=36 \mathrm{MPa}, Y_{\mathrm{C}}=230 \mathrm{MPa}, S=62 \mathrm{MPa}, a=b=0.5 \mathrm{~m}$, $h=5 \mathrm{~mm}$.

\subsection{Transverse bending}

The first ply failure loads were computed for the square composite plates having single and multiple delaminations of varying sizes for simply supported and clamped boundaries with a central point load. From the deflection values, stresses were calculated at every point in each layer of the laminate and applied to the Tsai-Wu failure criterion to check for failure. The first ply failure load for the various central mid-plane single delaminations are presented in tables 1 and 2 for the simply supported and clamped ends, respectively. Four different stacking sequences are considered here. From the tables, it was observed that the first ply failure load was reduced with the increase in the area of delamination.

Tables 3 and 4 show the first ply failure loads for increasing the number of central delaminations with $56.25 \%$ delamination area in each delamination interface

Table 1. First ply failure load for simply supported laminate (single delamination).

\begin{tabular}{lcccc}
\hline & \multicolumn{4}{c}{ First ply failure load $(N)$} \\
\cline { 2 - 5 } Delamination & $\left(\mathrm{O}_{5} /( \pm 30)_{5} / \mathrm{O}_{5}\right)$ & $\left(\mathrm{O}_{5} /( \pm 45)_{5} / \mathrm{O}_{5}\right)$ & $\left(\mathrm{O}_{5} /( \pm 60)_{5} / \mathrm{O}_{5}\right)$ & $\left(\mathrm{O}_{5} /( \pm 90)_{10} / \mathrm{O}_{5}\right)$ \\
\hline Zero & $1533 \cdot 5$ & $1898 \cdot 3$ & $2257 \cdot 0$ & $2533 \cdot 0$ \\
$6 \cdot 25 \%$ & $722 \cdot 0$ & $792 \cdot 5$ & $726 \cdot 0$ & $602 \cdot 0$ \\
$25 \%$ & $629 \cdot 0$ & $698 \cdot 0$ & $626 \cdot 0$ & $490 \cdot 0$ \\
$56 \cdot 25 \%$ & $579 \cdot 5$ & $639 \cdot 0$ & $560 \cdot 0$ & $416 \cdot 8$ \\
\hline
\end{tabular}

Table 2. First ply failure load for clamped laminate (single-delamination).

\begin{tabular}{lcccc}
\hline & \multicolumn{4}{c}{ First ply failure load $(N)$} \\
\cline { 2 - 5 } Delamination & $\left(\mathrm{O}_{5} /( \pm 30)_{5} / \mathrm{O}_{5}\right)$ & $\left(\mathrm{O}_{5} /( \pm 45)_{5} / \mathrm{O}_{5}\right)$ & $\left(\mathrm{O}_{5} /( \pm 60)_{5} / \mathrm{O}_{5}\right)$ & $\left(\mathrm{O}_{5} /( \pm 90)_{10} / \mathrm{O}_{5}\right)$ \\
\hline Zero & $1847 \cdot 0$ & $2280 \cdot 0$ & $2748 \cdot 0$ & $3150 \cdot 0$ \\
$6 \cdot 25 \%$ & $883 \cdot 0$ & $952 \cdot 0$ & $849 \cdot 0$ & $7052 \cdot 0$ \\
$25 \%$ & $778 \cdot 0$ & $844 \cdot 8$ & $753 \cdot 5$ & $586 \cdot 0$ \\
$56 \cdot 25 \%$ & $722 \cdot 0$ & $779 \cdot 0$ & $668 \cdot 0$ & $513 \cdot 2$ \\
\hline
\end{tabular}

Table 3. First ply failure load for simply supported laminate (multiple delamination).

\begin{tabular}{lcccc}
\hline & \multicolumn{4}{c}{ First ply failure load $(N)$} \\
\cline { 2 - 5 } Delamination & $\left(\mathrm{O}_{5} /( \pm 30)_{5} / \mathrm{O}_{5}\right)$ & $\left(\mathrm{O}_{5} /( \pm 45)_{5} / \mathrm{O}_{5}\right)$ & $\left(\mathrm{O}_{5} /( \pm 60)_{5} / \mathrm{O}_{5}\right)$ & $\left(\mathrm{O}_{5} /( \pm 90)_{10} / \mathrm{O}_{5}\right)$ \\
\hline Zero & $1533 \cdot 5$ & $1898 \cdot 3$ & $2257 \cdot 0$ & $2533 \cdot 0$ \\
One & $579 \cdot 5$ & $639 \cdot 0$ & $560 \cdot 0$ & $416 \cdot 8$ \\
Three & $303 \cdot 0$ & $350 \cdot 0$ & $338 \cdot 0$ & $290 \cdot 0$ \\
Five & $122 \cdot 0$ & $144 \cdot 0$ & $162 \cdot 0$ & $173 \cdot 0$ \\
\hline
\end{tabular}

Table 4. First ply failure load for clamped laminate (multiple delamination).

\begin{tabular}{lcccc}
\hline & \multicolumn{4}{c}{ First ply failure load $(N)$} \\
\cline { 2 - 5 } Delamination & $\left(\mathrm{O}_{5} /( \pm 30)_{5} / \mathrm{O}_{5}\right)$ & $\left(\mathrm{O}_{5} /( \pm 45)_{5} / \mathrm{O}_{5}\right)$ & $\left(\mathrm{O}_{5} /( \pm 60)_{5} / \mathrm{O}_{5}\right)$ & $\left(\mathrm{O}_{5} /( \pm 90)_{10} / \mathrm{O}_{5}\right)$ \\
\hline Zero & $1847 \cdot 5$ & $2280 \cdot 0$ & $2748 \cdot 0$ & $3150 \cdot 0$ \\
One & $722 \cdot 0$ & $779 \cdot 0$ & $668 \cdot 0$ & $513 \cdot 2$ \\
Three & $372 \cdot 0$ & $419 \cdot 0$ & $402 \cdot 0$ & $356 \cdot 0$ \\
Five & $143 \cdot 0$ & $167 \cdot 0$ & $189 \cdot 5$ & $209 \cdot 0$ \\
\hline
\end{tabular}


for the simply supported and clamped ends, respectively. It was found that the increase in the number of delaminations sharply reduced the first ply failure load.

For all the single and multiple delaminations considered above, the first ply failure took place in the bottom most layer.

\subsection{Transverse impact}

Transient response was obtained for different plates using the converged time-step value of $1 \mu \mathrm{sec}$. For the present low velocity impact response analysis, an isotropic spherical impactor was considered for a centrally impacted composite plate. The impactor (spherical) properties are as follows

$$
E_{i}=210 \mathrm{GPa}, v_{i}=0 \cdot 3, \text { diameter }=1 \cdot 27 \mathrm{~cm} .
$$

For the first ply failure analysis, four different cases were considered here, where case 1 denotes no delamination, case 2 with a single delamination of $6.25 \%$ of the total plate area, case 3 with three delaminations and case 4 with five delaminations of same area in each delamination interface as in case 2.

For each case, the Tsai-Wu tensor polynomial value $(T)$ was calculated for every time-step during the impact. When this value just exceeded one, the velocity of impactor was denoted as critical impactor velocity, $V_{\mathrm{c}}$. Accordingly, $V_{\mathrm{c}}$ was determined for the laminates with different stacking sequences and delaminations. It gave a general inference about the delaminated laminates which could face an impactor without failure. For all the cases considered here, the first ply failure took place in the bottom most layer.

Figure 3 shows the variation of $T$ with respect to time for the top and bottom layers separately for a cross-ply

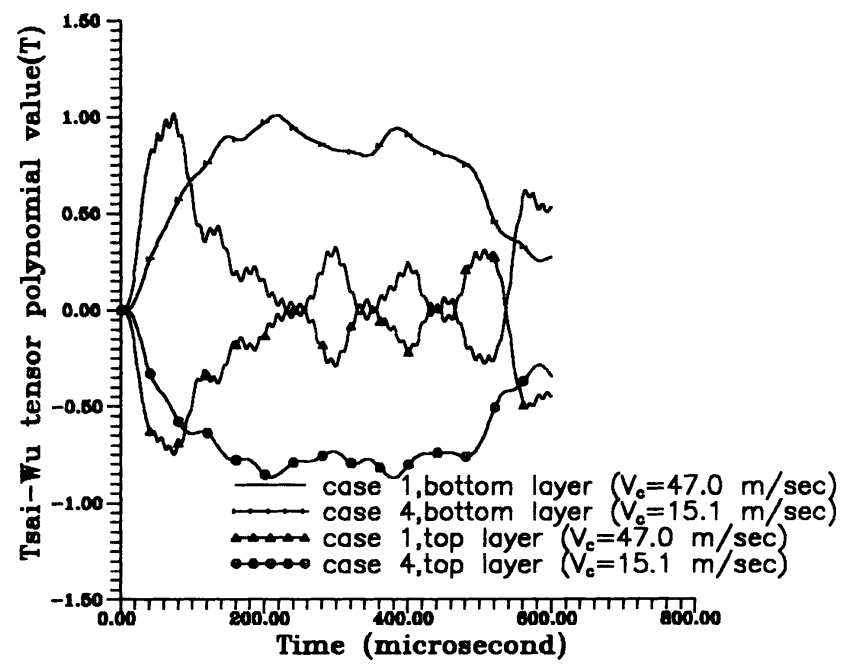

Figure 3. $T$ value for top and bottom layers for simply supported $\left(\mathrm{O}_{5} /(90)_{10} / \mathrm{O}_{5}\right)$ plate. laminate. In (20), $F_{1}$ value was zero and all other terms except the term $F_{2} \sigma_{2}$ yielded positive values. Hence the value of $\sigma_{2}$, which was of opposite sign in the top and bottom zones, controls the value of $T$ for different layers. So when the value of $T$ reaches towards positive value of 1 in the bottom layer, it was of the opposite sign for the top layer.

The plots for Tsai-Wu tensor polynomial value $(T)$ vs time for multiple delaminations are shown in figures 4 and 5 for simply supported cross-ply and angle-ply laminates, respectively. From these figures, it was very clear that the

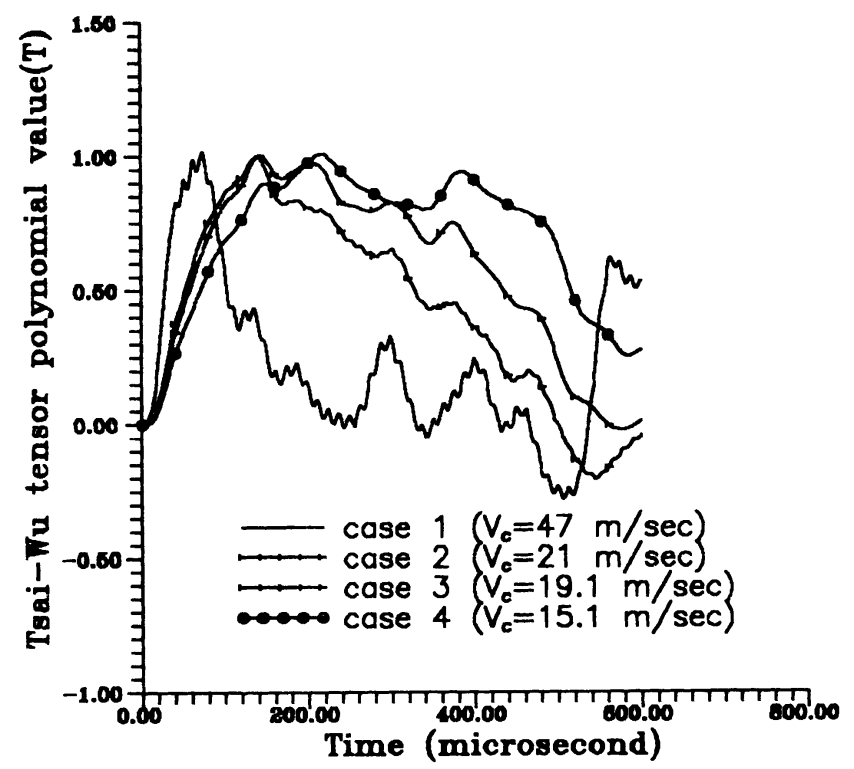

Figure 4. Critical impactor velocity $\left(V_{\mathrm{c}}\right)$ for different cases of simply supported $\left(\mathrm{O}_{5} /(90)_{10} / \mathrm{O}_{5}\right)$ plate.

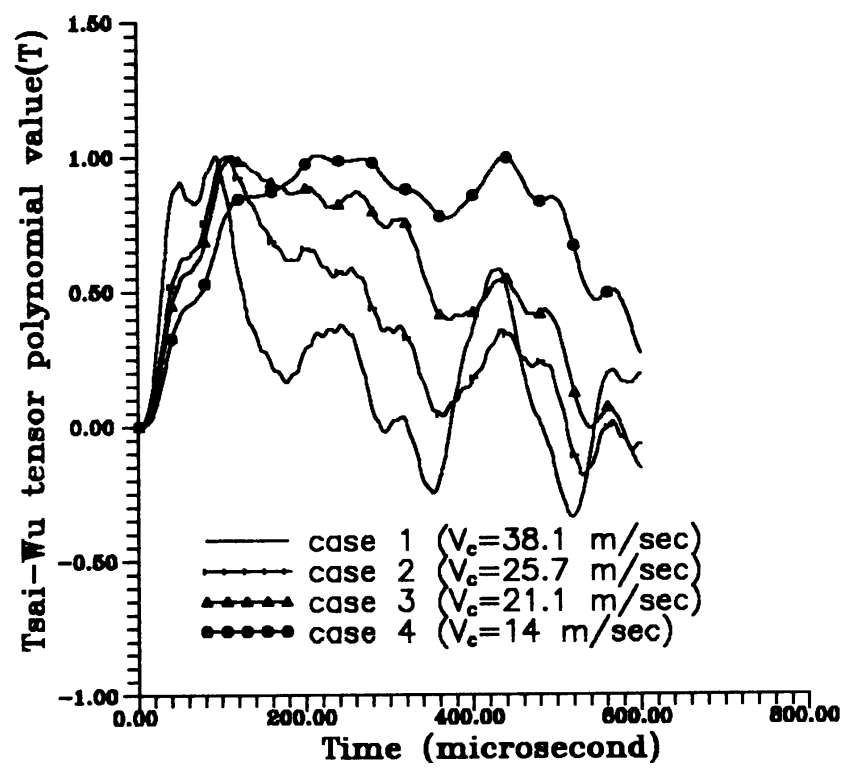

Figure 5. Critical impactor velocity $\left(V_{\mathrm{c}}\right)$ for different cases of simply supported $\left(\mathrm{O}_{5} /(45 /-45)_{5} / \mathrm{O}_{5}\right)$ plate. 


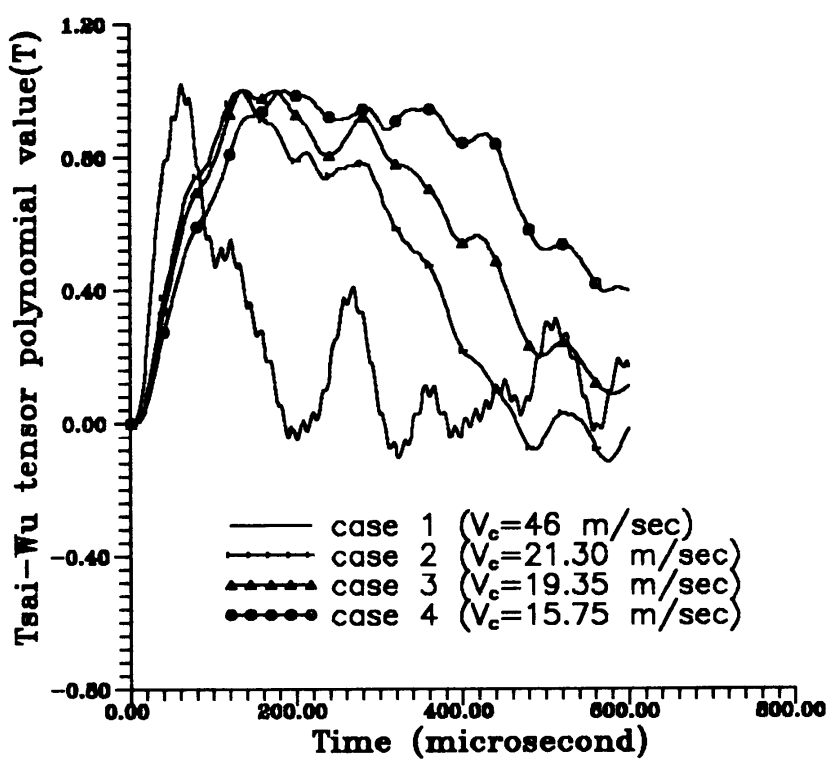

Figure 6. Critical impactor velocity $\left(V_{\mathrm{c}}\right)$ for different cases of clamped $\left(\mathrm{O}_{5} /(90)_{10} / \mathrm{O}_{5}\right)$ plate.

critical impactor velocity was minimum for case 4 (five delaminations) for all the laminates. For a laminate without delamination, $V_{\mathrm{c}}$ was maximum for a cross-ply, which was due to its higher stiffness value. The effect of change in boundary condition on the critical impactor velocity was also considered taking a clamped plate as shown in figure 6. There was no distinct change in the value of $V_{\text {c }}$ to cause first ply failure with a change in boundary condition.

\section{Conclusion}

It was observed that the delaminations were found to influence the first ply failure of the laminated composite plates significantly. For all the cases considered here the first ply failure took place in the bottom most layer only. From the analysis of the numerical results, it was observed that an increase in the number of delaminations resulted in a decrease in the transverse load for bending. In the case of impact, it resulted in a decrease in the critical impactor velocity to cause first ply failure. First ply failure load as well as the critical impactor velocity was found to be relatively more for a cross-ply laminate in comparison to an angle-ply laminate. It was also to be noted that the failure of the first ply was very sensitive to the strength constants and their variation in tension and compression. Hence, the performance of the laminates could be properly tailored by controlling the strength parameters for the design against failure.

\section{References}

Cook R D, Malkus D S and Plesha M E 1989 Concepts and applications of finite element analysis (New York: John Wiley and Sons)

Krawczuk M, Ostachowicz W and Zak A 1997 Comp. Mech. 20 79

Lee J, Gurdal Z and Griffin O H Jr 1992 AIAA J. 31331

Lee J, Gurdal Z and Griffin O H Jr 1995 AIAA J. 101963

Paolozzi A and Peroni I 1990 J. Reinf. Plast. Compos. 9369

Parhi P K, Bhattacharyya S K and Sinha P K 1999 J. Reinf. Plast. Compos. (in press)

Saravanos D A and Hopkins D A 1996 J. Sound Vibrat. 192 977

Shen M H H and Grady J E 1992 AIAA J. 301361

Tenek L H, Henneke II E G and Gunzburger M D 1993 Compos. Struct. 23253

Tracy J J and Pardoen G C 1989 J. Compos. Mater. 231200

Tsai S W and Hahn H T 1980 Introduction to composite materials (Lancaster: Technomic Publishing Company Inc)

Yang S H and Sun C T 1982 ASTM STP 787 (Philadelphia, PA: American Society for Testing and Materials) p. 425

Yin W L, Sallam S and Simitses G J 1986 AIAA J. 24123 